Bol. Acad. peru. leng. 62. 2017 (111-121)

\title{
El entrelugar en la literatura latinoamericana: los casos de César Moro y José María Arguedas
}

\section{The space in-between in the Latin American literature: the case of Cesar Moro and Jose Maria Arguedas}

\section{Camilo Rubén Fernández Cozman \\ Universidad de Lima}

Resumen:

No hay una identidad cultural, siempre hay identidades culturales que responden a sujetos descentrados que hablan desde diversas posiciones discursivas. El entrelugar es una categoría sustentada por Silviano Santiago con el propósito de plantear que el sujeto no habla desde un locus específico, sino desde diversos lugares. César Moro castellanizó el francés en tanto que José María Arguedas quechuizó el castellano. Sin embargo, ambos evidencian una crítica de la invasión española, cuestionamiento que se da desde diversas perspectivas. Para ello, se hará la comparación entre «Biografía peruana (muralla de seda)» de Moro y algunos pasajes de Los ríos profundos de Arguedas con el fin de plantear el papel que asume el escritor latinoamericano en una sociedad poscolonial como la peruana. 


\section{Abstract:}

There is no cultural identity, there are always cultural identities that belonged to decentered subjects talking from different discursive positions. The space in-between is a category supported by Silviano Santiago to consider that a subject does not speak from a specific locus, but from different places. Cesar Moro Hispanized French as to Jose Maria Arguedas Quechuasized Spanish. However, both are a critique of the Spanish invasion, questioning what is happening from different perspectives. In order to do this, "Biografía peruana (muralla de seda)" ("Peruvian biography the wall of silk") by Moro and some passages of "Los ríos profundos" ('Deep rivers') by Arguedas will be analyzed in order to consider the role assumed by the Latin American writer in a postcolonial society such as the Peruvian.

Palabras clave: César Moro, José María Arguedas, literatura latinoamericana, identidad cultural, entrelugar.

Keywords: Cesar Moro, Jose Maria Arguedas, Latin American literature, cultural identity, space in-between.

Recibido: 15/09/2017

Aceptado: 20/10/2017

¿De qué manera los escritores latinoamericanos se relacionan con las culturas europeas? ¿Son, acaso, simples imitadores o creadores en el más ilustre sentido de la palabra? Silviano Santiago afirma sin ambages que 
La mayor contribución de América Latina a la cultura occidental viene de la destrucción sistemática de los conceptos de unidad y de pureza: estos dos conceptos pierden el contorno exacto de su significado, pierden su peso opresor, su signo de superioridad cultural, a medida que el trabajo de contaminación de los latinoamericanos se afirma, se muestra cada vez más eficaz (2000: 67-68).

La obra de los poetas, narradores y dramaturgos latinoamericanos implica el funcionamiento de una violencia verbal y, por ello, la reestructuración creativa de los aportes de las culturas europeas. Los ejemplos son innumerables. César Vallejo desestructura el soneto modernista de Rubén Darío (cuyas fuentes obvias se hallan en la poesía francesa decimonónica) en el poema «Idilio muerto» ante el impacto del referente andino, debido a que el poeta peruano considera que no se puede hablar de la «andina y dulce Rita» a través de un código literario que implica un acrítica asimilación de los aportes de las literaturas europeas. Octavio Paz, en «Piedra de sol», se nutre creativamente del surrealismo, pero inmediatamente lo reestructura a través del empleo del tiempo circular de las civilizaciones mesoamericanas y de los 584 versos que equivalen a los días del calendario de los antiguos mexicanos (Fernández 2015). Pablo Neruda, en Canto general, deconstruye el poema épico clásico y lo transforma en una épica contemporánea latinoamericana, pues es su obligación la de hablar de las civilizaciones amerindias en el tejido de la historia social de América Latina. Jorge Luis Borges, en «Funes el memorioso», medita sobre la memoria y el proceso de adquisición de conocimiento; pero lo hace desde la posición de un autor periférico 
que pone de relieve la postura de Funes, un uruguayo que vive en un pobre arrabal latinoamericano. Joaquim Maria Machado de Assis se burla de la retórica clásica en su célebre relato «El alienista» y se propone carnavalizar los aportes de esta última; asimismo, en Memorias de Bras Cubas ironiza la idea de trascendencia vinculada al imaginario católico: el narrador dedica su obra a los gusanos que royeron su cadáver.

Santiago subraya que:

Entre el sacrificio y el juego, entre la prisión y la transgresión, entre la sumisión al código y la agresión, entre la obediencia y la rebelión, entre la asimilación y la expresión, allí, en ese lugar aparentemente vacío, su templo y su lugar de clandestinidad, allí se realiza el ritual antropófago de la literatura latinoamericana (2000: 77).

El propósito principal de este escueto artículo es hacer una primera reflexión acerca del entrelugar de la literatura latinoamericana a través del análisis de dos textos, uno de Arguedas y otro de Moro: un fragmento de la célebre novela Los ríos profundos y el ensayo «Biografía peruana (la muralla de seda)». Tanto Moro como Arguedas vivieron en carne propia el bilingüismo. El primero aprendió el francés e hizo de este su lengua literaria; el segundo aprendió el español y optó por dicho código en la narrativa, mas reservó el quechua para su poesía. En una sociedad atravesada por el proceso de la Conquista española y la imposición de las culturas occidentales sobre las andinas, es una decisión compleja la de quechuizar el castellano (Arguedas) o de castellanizar el francés (Moro). 
Uno de los fragmentos más cautivantes de Los ríos profundos es el que cuenta la visita de Ernesto y su padre al palacio de Inca Roca. El narrador personaje contrapone la construcción de tipo colonial a la muralla inca: «En la calle angosta, la pared española, blanqueada, no parecía servir sino para dar luz al muro» (Arguedas 1978: 12). Se trata de la oposición entre lo occidental y lo andino, que es reconocida por Ernesto: pareciera que ambos espacios culturales fueran complementarios. No obstante, aflora inmediatamente el «caos creativo» de Ernesto:

-Papá -le dije-. Cada piedra habla. Esperemos un momento.

-No oiremos nada. No es que hablan. Estás confundido. Se trasladan a tu mente y desde allí te inquietan.

(Arguedas 1978: 12)

La posibilidad de la fecunda oralidad quiebra un tipo de racionalidad basada en el ejercicio de la escritura y, en tal sentido, se manifiesta una concepción de tiempo absolutamente disímil: Ernesto espera un momento y ello significa cumplir un rito frente a la divinidad hecha piedra, como si aguardara, con fe, la manifestación de la palabra sagrada. Súbitamente, el padre de Ernesto se aferra a la religión católica y a la racionalidad sustentada en la escritura («No oiremos nada»), por eso, trata de «tranquilizar» a su hijo. Es sintomático que utilice la expresión «Estás confundido» porque le preocupa ese «caos creativo» que cuestiona el imaginario hegemónico, determinado por la escritura y la religión católica. La escena siguiente resulta muy sugestiva: 
—Los incas están muertos.

-Pero no este muro. ¿Por qué no lo devora, si el dueño es avaro? Este muro puede caminar: podría elevarse a los cielos o avanzar hacia el fin del mundo y volver. ¿No temen quienes viven adentro?

-Hijo, la catedral está cerca. El Viejo nos ha trastornado. Vamos a rezar.

-Dondequiera que vaya, las piedras que mandó formar Inca Roca me acompañarán. Quisiera hacer aquí un juramento.

— ¿Un juramento? Estás alterado, hijo. Vamos a la catedral. Aquí hay mucha oscuridad (Arguedas 1978: 12-13).

El padre, nuevamente, procura dar tranquilidad a su hijo aferrándose a ritos católicos. Ernesto está lleno de preguntas y revela una visión cíclica: el fin del mundo implica un retornar, vale decir, el acto de regenerar el cosmos de modo incontenible. La expresión «Este muro puede caminar» implica el triunfo del cuestionamiento de las culturas occidentales porque transgrede creativamente la habitual forma de organizar impuesta por los grupos hegemónicos. Las piedras acompañarán a Ernesto y este desea hacerles un juramento. Las relaciones entre aquellas y los seres humanos se establecen sobre la base de la reciprocidad. Se hace una promesa a las piedras y estas, a cambio, ofrecerán compañía a Ernesto. El padre se aferra a una estructura impuesta por los conquistadores y busca dar calma al hijo. La solución es previsible: se impone el rito católico («Vamos a la catedral») y, por ello, se califica el espacio, donde Ernesto hará un juramento, como oscuro y confuso; pero, en realidad, Ernesto revela el entrelugar del sujeto en Latinoamérica. Su postura evidencia el «ritual antropófago» del latinoamericano (término acuñado por Silviano Santiago, pero que remite a 
Oswald de Andrade): Ernesto se rebela y despliega su imaginación acorde con el pensar mítico andino. Se trata de una transgresión y un profundo cuestionamiento de la imposición de la cultura occidental sobre la andina.

En «Biografía peruana (la muralla de seda)», Moro reflexiona sobre el aporte de dos culturas: la occidental (representada por el simbolismo de Stéphane Mallarmé) y la andina (encarnada en el templo del Sol): «Se conoce el hecho escandaloso del disco de oro del Sol del templo del Cusco jugado y perdido a los dados por un soldado al día siguiente del saqueo al templo. Un golpe de dados no abolirá nunca el azar» (2002: 334). Analicemos la lectura latinoamericana que nuestro poeta hace del legado de Mallarmé y cómo emplea el título de una célebre obra de este para cavilar acerca de la violencia cultural que se estableció en el Cusco. Se trata de un Mallarmé representado por un poeta bilingüe que, sabiendo el francés y usándolo como vehículo privilegiado de expresión poética, medita acerca de cómo se impuso el castellano, junto al catolicismo, sobre el quechua y la religión andina.

El soldado español juega con un elemento sagrado de la religión andina, es decir, con el disco de oro del Sol. En tal sentido, lo mítico y sacro se han convertido, para este hombre occidental, en un objeto materia de un juego absolutamente baladí. Saquear el templo significa atentar contra los dioses andinos y convertir el disco de oro en una mera «cosa» desprovista de su valor y solemnidad rituales. Hemos pasado del rito a la automatización lúdica (y no creativa). Se trata de un evento, regido por el azar, que denota la agresividad del conquistador en desmedro de la cultura andina (Fernández 2012). 
No obstante, la alusión al título del poema de Mallarmé resulta altamente significativa de cómo César Moro se convierte en un antropófago de la cultura occidental. Se nutre violentamente del aporte de la poesía simbolista francesa, pero lo emplea para retratar una situación marcada por la violencia. Para Mallarmé, la jugada de dados tenía que ver con la poética musical que jugaba con el espacio de la página en blanco y así se anticipaba a la estética cubista; para Moro, el título «Una jugada de dados jamás abolirá el azar» tiene que ser repensado en Latinoamérica a la luz de la imposición de la cultura occidental sobre la indígena. Se trata de plantear, metafóricamente sin duda, la noción de que no es posible abolir (léase eliminar) el culto al Sol y que el hombre andino resistirá la agresión realizada por el conquistador español. En otras palabras, Moro hace una interpretación antropológica del título del poema mallarmeano y lo sitúa en el contexto peruano. Aquí los versos simbolistas de Mallarmé posibilitan una hermenéutica política porque implican interpretar y calibrar la violencia del conquistador y su poca disposición para materializar un diálogo intercultural. Se impone la escritura sobre la oralidad. El catolicismo busca derribar el templo del Sol y todos los ritos andinos.

Moro percibe que el Perú se halla en ruinas luego de la conquista española e inmediatamente pasa a relatar una experiencia invalorable, vale decir, el viaje que hizo en 1937 a Huánuco: «El Valle de la Quinua nos conducía hacia el jardín de Huánuco rodeado de montañas de tierra azul, verde, púrpura y roja, sin paráfrasis» (2002: 335). Es digno de interés cómo valora dicha vivencia y alude a «un viaje de sueño que 
hizo sobre los Andes para llegar a Huánuco» (2002: 335), pero luego, como si estuviera buscando dar una imagen totalizante del Perú, pasa a referirse a la costa del Perú y recuerda, nostálgico, las playas de Conchán, de Pucusana y Ancón. La idea es ostensible: sierra y costa forman parte del Perú, pero lamentablemente la vida estandarizada hace que se vayan perdiendo las tradiciones ancestrales. Se trata de la modernización que, muchas veces, atenta contra los ritos que terminan desapareciendo, cuando nuestra identidad nacional se sustenta en estos rituales que construyen la memoria colectiva de un pueblo.

El final del ensayo no deja de ser conmovedor. El poeta está regresando al Cusco: «Viajo de noche nuevamente hacia el muro de seda. La piedra de los doce ángulos centellea destacada sobre el cielo estrellado: constelación de la mano de hombre» (Moro 2002: 337). Se pregunta si los tesoros de la cultura inca que, para Moro, son también «tesoros anímicos», se mantendrán o se perderán en la arena del olvido. Califica a lo occidental como banal y al pasado inca como maravilloso. Luego habla de «un país sordo y ciego» (Moro 2002: 337), es decir, de un Perú que no escucha el canto de la piedra ni los rituales que constituyen el ser colectivo en nuestro país. Moro parece decirnos que no queremos escuchar al otro. Nos solazamos en una especie de solipsismo y dejamos de lado el fecundo diálogo intercultural. Escuchar al otro abre también la posibilidad de escucharnos a nosotros mismos, porque la identidad se construye sobre la base de la alteridad. Si reconocemos el poder de la palabra del otro, entonces podremos construir una identidad basada 
en la pluralidad lingüística y cultural. He ahí el proyecto que subyace a «Biografía peruana (la muralla de seda)».

Arguedas habla del templo de Inca Roca; Moro, del templo del Sol. En ambos se observa la presencia imponente de las culturas andinas. Santiago afirma que, para el escritor latinoamericano: «Es necesario que aprenda primero a hablar de la lengua de la metrópoli para inmediatamente combatirla mejor» (2000: 72). Moro y Arguedas, cada uno a su manera, ejercen la violencia verbal con el fin de desmitificar, de manera profunda y convincente, el aporte de las culturas europeas. Así, forjan, con los pedazos y fragmentos siempre fulgurantes, una nueva cultura. 


\section{Bibliografía}

ARGUEDAS, José María. Los ríos profundos. Buenos Aires, Editorial Losada, 1978.

FERNÁNDEZ COZMAN, Camilo. César Moro, ¿un antropófago de la cultura? Lima, Revuelta Editores, 2012.

- El cántaro y la ola. Una aproximación a la poética de Octavio Paz. Segunda edición. Huaraz, Killa Editorial, 2015.

MORO, César. Prestigio del amor. Selección, traducción y prólogo de Ricardo Silva-Santisteban. Lima, Pontificia Universidad Católica del Perú, 2002.

SANTIAGO, Silviano. «El entrelugar del discurso latinoamericano», en AMANTE, Adriana y Florencia GARRAMUÑO (eds.). Absurdo Brasil: polémicas en la cultura brasileña. Buenos Aires, Biblos, 2000, págs. 61-77. 